\title{
Muhammadiyah dalam Perkembangan Pendidikan Islam di Indonesia
}

\author{
Azaz Akbar ${ }^{1}$, A. Rezky Nurhidaya $S^{2}$, A.Muh Ali ${ }^{3}$, Syarifuddin Ondeng ${ }^{4}$ \\ ${ }^{1,3}$ Universitas Muhammadiyah Buton, Indonesia \\ ${ }^{2}$ Universitas Islam Makassar, Indonesia \\ ${ }^{4}$ Universitas Islam Negeri Alauddin Makassar, Indonesia \\ *azaz.akbar23@gmail.com, ${ }^{2}$ andirezkynurhidayahrere@yahoo.com, ${ }^{3}$ andiali649@gmail.com³
}

\begin{tabular}{|l|l|l|}
\hline Receive: 03/08/2021 & Accepted: 20/09/2021 & Published: 01/10/2021
\end{tabular}

\begin{abstract}
Abstrak
Muhammadiyah merupakan organisasi yang didirikan oleh Kyai Ahmad Dahlan yang banyak bergerak pada amal usaha dibidang pendidikan seperti sekolah PAUD/, TK, SD, SLTP, SLTA, dan Perguruan Tinggi. Tujuan dari penelitian ini adalah untuk memberikan kajian singkat dari beberapa artikel penelitian yang membahas tentang pergerakan muhammadiyah dari latar belakang berdirinya hingga pengaruhnya dalam dunia pendidikan islam di Indonesia. Metode penelitian ini yaitu studi kepustakaan Kerena pada akhirnya seluruh bahan yang telah dibaca harus ditarik sebuah kesimpulan dalam bentuk laporan. Sumber data terdiri dari data primer dan data sekunder. Hasil penelitian ini menunjukkan bahwa kemunculan organisasi muhammadiyah merupakan respon dari penegakkan ajaran islam yang berangkat dari al-Quran dan Sunnah. Juga dari sekian factor yang dikemukakan dari kedua penelitian tersebut di atas adalah tentang pemurnian tauhid yang dipengaruhi oleh colonialism tentang syirik, takhyul, bid'ah dan khurafat dan dhidup dalam kemiskinan, kemelaratan dan kebodohan. organisasi Muhammadiyah sangat memperhatikan kondisi masyarakat yang majemuk dalam pengembangan kurikulum Pendidikan di Indonesia.
\end{abstract}

Kata Kunci: Muhammadiyah, Pendidikan Islam, Indonesia

\begin{abstract}
Muhammadiyah is an organization founded by Kyai Ahmad Dahlan which is mostly engaged in business charities in the field of education such as PAUD/TK, SD, SLTP, SLTA, and Universities. The purpose of this study is to provide a brief review of several research articles that discuss the Muhammadiyah movement from its founding background to its influence in the world of Islamic education in Indonesia. This research method is a literature study because in the end all the material that has been read must be drawn a conclusion in the form of a report. Data sources consist of primary data and secondary data. The results of this study indicate that the emergence of the Muhammadiyah organization is a response to the enforcement of Islamic teachings that depart from the Qur'an and Sunnah. Also of the factors raised from the two studies above are about the purification of monotheism which was influenced by colonialism regarding shirk, superstition, bid'ah and superstition and living in poverty, destitution and ignorance. Muhammadiyah organization is very concerned about the condition of a pluralistic society in the development of the education curriculum in Indonesia.
\end{abstract}

Keywords: Muhammadiyah, Islamic Education, Indonesia 
Jurnal Edumaspul, 5 (2), Year 2021 - 899

(Azaz Akbar, A. Rezky Nurhidaya S, A.Muh Ali, Syarifuddin Ondeng)

\section{Pendahuluan}

Perjalanan sejarah pendidikan di Indonesia menjadi diskursus yang tidak ada akhirnya. Dalam dimensi sejarah, terdapat tiga bagian yang selalu bergerak bagai roda kehidupan, yaitu masa lalu, masa kini dan masa yang akan datang. Tinjauan sejarah juga terkadang menimbulkan persepsi yang parsial pada masyarakat bila sejarawan tidak objektif melahirkan informasi.

Kemajuan ilmu pengetahuan, teknologi, dan seni yang begitu pesat, arus globalisasi yang begitu hebat, melahirkan manusia yang larut dalam arus peradaban. Perjalanana pradaban bangsa terkadang dipoles dengan desain yang diinginkan oleh sekelompok orang yang kurang bijaksana tanpa harus berlaku adil dan jujur sehingga manusia sulit mendapatkan pelajaran dari masa lalunya.

Sebuah buku dengan judul "Selekta Kapita Pendidikan Islam" menjelaskna bahwa terdapat lima faktor yang memberikan corak dan dinamika pendidikan Islam di Indonesia. Kelima faktor itu yaitu; Pertama, perkembangan

masyarakat, Kedua, perkembangan ilmu pengetahuan

dan

teknologi , Ketiga, perkembangan

ekonomi, Keempat, perkembangan agama dan budaya masyarakat di mana pendidikan tersebut dilaksanakan, dan Kelima, perkembangan politik [1].

Perkembangan kemajuan pendidikan indonesia setidaknya dapat dilihat secara bertahap seperti menaiki anak tangga yang runtun. Dimulai dari masa VOC, penjajahan jepang, hingga masa kemerdekaan yang ditandai dengan orde lama, orde baru dan revormasi. Sejalan dengan itu dijelaskan pula bahwa pendidikan di Indonesia melalui proses dari VOC, Hindia Belanda, Politik Etis, Zaman Pendudukan Jepang, Zaman Kemerdekaan, Orde Lama, Orde Baru, maupun Era Reformasi [2].
Berbagai organisasi lokal pada masa ini terus berupaya untuk menjaga stabilitas pengaruh yang menyimpang. Seperti misalnya Muhammadiyah, Nahdatul Ulama, dan organisasi lainya. Terlihat sangat jelas peran Muhammadiyah dalam kemajuan pendidikan di Indonesia. Dengan terbentuknya Muhammadiyah maka sistem pendidikan di Indonesia menjadi lebih fleksibel dengan pendidikan yang berbasis pada agama yang diajarkan di pesantren dan pendidikan non agama yang diselenggarakan oleh sekolah yang didirikan bangsa Belanda.

Muhammadiyah mengkondisikan sistem pendidikan klasik dan modern sehingga pada awal-awal perkembanganya banyak mendapat penentangan dari berbagai kalangan khususnya yang berpandangan inklusif. Peranan Muhammadiyah yang berpartisipasi dalam pembinaan generasi muda Islam, adalah suatu hal yang sangat penting. Terlebih karena pionirnya, K.H. Ahmad Dahlan merupakan seorang ulama muda yang menaruh perhatian begitu besar bagi perkembangan generasi muda Islam, pada tahun 1909 ia memasuki sebuah organisasi kaum muda Budi Utomo dengan harapan ia dapat memulai karirnya sebagai pengajar agama di sekolah-sekolah pemerintah [3] .

Muhammadiyah sebagai organisasi yang didirikan tanggal 18 November 1912 di Yogyakarta yang kemudian dengan cepat menyebar keseluruh Indonesia [4]. Merupakan organisasi dakwah memberikan pengaruh yang cukup besar dalam perkembangan pendidikan di Indonesia. Setidaknya bisa kita temukan fakta yang membuktikan argumentasi itu yaitu banyaknya Amal Usaha Muhammadiyah (AUM) yang bergerak dalam dunia pendidikan. Media Republika yang diterbitkan pada Jum'at 26 November 2021 menyebutkan Muhammadiyah dan bisnisnya (AUM) terdapat 10.368 unit yang terdiri atas 
TK/PAUD, SD/MI, SMP/MTs, SMA/SMK/MA, perguruan tinggi, rumah sakit, serta berbagai bisnis sosial lainya [5].

Banyak orang yang mengira, kebesaran jumlah amal usaha yang dimiliki persyarikatan itu karena sokongan dan sumbangan dana dari Pimpinan Pusat (PP) Muhammadiyah [6]. Padahal PP Muhammadiyah hanya memberi sokongan moral, arah, orientasi, dan motivasi untuk melangkah sesuai koridor. Lebih dari itu, adanya aturan organisasi yang diputuskan bersama dan kepemimpinan kolektif-kolegial yang menjadi semen perekat pergerakan.

Para aktivis Muhammadiyah di tingkat akar rumput, misalnya di ranting atau cabang selalu terdoktrin untuk selalu berlombalomba demi kebaikan (fastabiqul khaerat). Maka, antara ranting dan cabang selalu ingin berlomba dan terobsesi membuat amal kebajikan. Tidak heran, jika Amal Usaha Muhammadiyah (AUM) bertebaran di seantero negeri. Mulai dari sekolah (PAUD, TK, SD, SLTP, SLTA), Perguruan Tinggi, Rumah Sakit, Klinik, Panti Asuhan/Jompo, Rumah Singgah, Koperasi, Retail, Dana Pensiun, Persero, Jaringan Tani/Nelayan, Jaringan Usaha, Lazis, Wakaf, Hibah, dan seterusnya [6].

Diskurusus tentang sejarah panjang Muhammadiyah dalam membangun sistem pendidikan di Indonesia menjadi sesuatu yang menarik untuk terus dikaji, mengingat muhammadiyah mengambil peran yang besar dalam menjaga keutuhan NKRI melalui pendidikan [7].

Penelitian ini berangkat dari kekhawatiran penulis dari kesalahan dalam penafsiran tentang sejarah. Dasar pemikiran yang akan dibangun pada peelitian ini adalah kajian singkat tentang simpulan dari beberapa penelitian yang menggambarkan latar belakang pendirian muhammadiyah dan pandangan muhammadiyah dalam dunia pendidikan.
Penelitian ini merupakan jenis riset kepustakaan (library research). Apa yang disebut dengan riset kepustakaan atau sering juga disebut studi pustaka, ialah serangkaian kegiatan yang berkenaan dengan metode pengumpulan data pustaka, membaca dan mencatat serta mengolah bahan penelitian [8]. Adapun tahap-tahap yang harus ditempuh penulis dalam penelitian kepustakaan adalah sebagai berikut: Pertama Mengumpulkan bahan-bahan penelitian dengan mencari kata kunci yang relevan dengan penelitian ini melalui jurnal penelitian juga berupa informasi atau data empirik yang bersumber dari buku-buku, hasil laporan penelitian resmi maupun ilmiah dan literatur lain yang mendukung tema penelitian ini. Kedua Membaca bahan kepustakaan. Ketiga Membuat catatan penelitian. Kegiatan mencatat bahan penelitian boleh dikatakan tahap yang paling penting dan barang kali juga merupakan puncak yang paling berat dari keseluruhan rangkaianbpenlitian kepustakaan. Kerena pada akhirnya seluruh bahan yang telah dibaca harus ditarik sebuah kesimpulan dalam bentuk laporan.

Subjek penelitian ini adalah organisasi Muhammadiyah, sedang objeknya adalah perkembangan pendidikan Islam di Indonesia. Penelitian ini menggunakan pendekatan kualitatif karena sumber data maupun hasil penelitian dalam penelitian kepustakaan (library research) berupa deskripsi kata-kata.

Sumber data dari penelitian ini terdiri dari data primer dan data sekunder. Data primer yaitu data yang diperoleh dari karya ilmiah yang diterbitkan baik dalam bentuk jurnal penelitian, prosiding maupun dalam karya skripsi, tesis, dan disertasi. Sedangkan data sekunder terdiri dari buku-buku yang relefan dengan bahan kajian dalam penelitian ini.

\section{Hasil dan Pembahasan}

\section{Metode}


Nelli Yusra menjelaskan dalam penelitianya tentang Muhammadiyah, bahwa cikal bakal berdirinya organisasi Muhammadiyah adalah dari sekian banyak faktor yang melatar belakangi berdirinya Muhammadiyah, setidaknya tersimpul dalam empat faktor yang utama. Pertama, ketidak bersihan dan campur aduk kehidupan agama Islam di Indonesia. Kedua, ketidak efisienan lembaga-lembaga pendidikan Islam Indonesia. Ketiga, aktifitas misi-misi Khatolik dan Protestan. Keempat, sikap acuh tak acuh, malah kadang-kadang sikap merendahkan golongan intelegensia terhadap Islam. Sementara Achmad Jainuri menambahkan bahwa faktor eksternal kelahiran Muhammadiyah selain berkaitan dengan politik Belanda terhadap kaum muslimin Indonesia, juga karena pengaruh ide dan gerakan di Timur Tengah, dan juga kesadaran beberap pemimpin Islam terhadap kemajuan yang telah dicapai oleh Barat.

Nurlaila Al Aydrus mengemukakan dalam penelitianya bahwa Muhammadiyah merupakan gerakan yang kelahirannya diilhami dan disemangati oleh ajaran AlQur'an dan seluruh geraknya tidak ada motif lain kecuali semata-mata untuk merealisasikan prisnip-prinsip ajaran Islam. Jadi, segala apa yang dilakukan tidak lepas dari ajaran Islam. Berdasarkan pengertian ini, pantaslah Muhammadiyah disebut dengan gerakan Islam, karena kelahirannya merupakan hasil konkret dari telaah K.H. Ahmad Dahlan terhadap al-Qur'an dan pemikiran-pemikiran tokoh-tokoh pembaharu Timur Tengah seperti Ibn Qoyyim al-Jauziyah, Ibn Taiymiyah, Syekh Muhammad Abduh Rasyid Ridho dan lainlain, serta didorong oleh teman-teman dari Budi Utomo, maka K.H. Ahmad Dahlan mendirikan organisasi Muhammadiyah. Disamping itu, kelahiran Muhammadiyah juga sebagai reaksi terhadap kondisi kehidupan sosial bangsa dan sosial keagamaan kaum muslimin di Indonesia yang pada waktu itu meringkuk di bawah penjajahan kolonial Belanda dan penjajahan pemikiran yang ditandai dengan meraja lelanya perbuatan syirik, takhyul, bid'ah dan khurafat dan hidup dalam kemiskinan, kemelaratan dan kebodohan.

Dari kedua penelitian ini dapat ditarik benang merah bahwa kemunculan organisasi Muhammadiyah merupakan respon dari penegakkan ajaran Islam yang berangkat dari al-Qur'an dan Sunnah. Juga dari sekian factor yang dikemukakan dari kedua penelitian tersebut di atas adalah tentang pemurnian tauhid yang dipengaruhi oleh kolonialisme tentang syirik, takhyul, bid'ah dan khurafat dan hidup dalam kemiskinan, kemelaratan dan kebodohan.

\section{Pendidikan \\ Pandangan Muhammadiyah Tentang}

Menurut Muhammadiyah pendidikan bisa dikatakan sebagai wahana untuk mempersiapkan manusia didalam memecahkan problem kehidupan pada masa kini maupun masa yang akan datang. Oleh karena itu, sistem pendidikan yang baik harus disusun atas dasar kondisi lingkungan masyarakat, baik kondisi masa kini maupun antisipasi masa mendatang. Perubahan kondisi lingkungan merupakan tantangan dan peluang yang harus direspon secara tepat dan memberikan nilai tambah. [9]. Penting bagi perkembangan pendidikan Islam Indonesia. Muhammadiyah menyempurnakan kurikulum pendidikan Islam dengan mamasukkan pendidikan agama Islam ke dalam sekolah umum dan pengetahuan sekuler ke sekolah agama [10].

Kedua pendapat di atas dapat disimpulkan bahwa organisasi Muhammadiyah sangat memperhatikan kondisi masyarakat yang majemuk dalam pengembangan kurikulum pendidikan di Indonesia. Muhammadiyah terus berbenah untuk menjaga eksistensinya dalam memajukan pendidikan di Indoneisa ditandai dengan arah pendidikan ala Muhammadiyah yang konsen menjawab tantangan dan menjemput peluang. 
Jurnal Edumaspul, 5 (2), Year 2021 - 902

(Azaz Akbar, A. Rezky Nurhidaya S, A.Muh Ali, Syarifuddin Ondeng)

Terdapat dua penelitian yang menjadi fokus kajian dalam penelitian ini yakni artikel penelitian dengan Muhammadiyah: Gerakan Pembaharuan Pendidikan Islam dan Peran Muhammadiyah dalam Upaya Pengembangan Pendidikan Islam di Indonesia. judul karya dan karya.

Tabel nama jurnal yang diteliti

\begin{tabular}{|c|c|c|c|}
\hline No & $\begin{array}{c}\text { Nama } \\
\text { Penulis }\end{array}$ & Judul & Penerbit \\
\hline 1 & $\begin{array}{l}\text { Nelly } \\
\text { Yusra }\end{array}$ & $\begin{array}{l}\text { Muhammadiy } \\
\text { ah: Gerakan } \\
\text { Pembaharuan } \\
\text { Pendidikan } \\
\text { Islam }\end{array}$ & $\begin{array}{l}\text { POTENSIA: } \\
\text { Jurnal } \\
\text { Kependidi } \\
\text { kan Islam }\end{array}$ \\
\hline 2 & $\begin{array}{l}\text { Nurlaila } \\
\text { Al } \\
\text { Aydrus, } \\
\text { Nirmala, } \\
\text { dan } \\
\text { Adhrians } \\
\text { yah } \\
\text { A.Lasawa } \\
\text { li. }\end{array}$ & $\begin{array}{l}\text { Peran } \\
\text { Muhammadiy } \\
\text { ah dalam } \\
\text { Upaya } \\
\text { Pengembanga } \\
\text { n Pendidikan } \\
\text { Islam di } \\
\text { Indonesia }\end{array}$ & $\begin{array}{l}\text { IQRA : } \\
\text { Jurnal } \\
\text { Ilmu } \\
\text { Kependidi } \\
\text { kan dan } \\
\text { Keislaman }\end{array}$ \\
\hline
\end{tabular}

\section{Simpulan}

Kemunculan organisasi Muhammadiyah sebagai Gerakan dakwa amal ma'ruf nahi mungkar sebagai respon dari penjajah belanda sekaligus penegakkan ajaran Islam yang berangkat dari al-Quran dan Sunnah. Muhammadiyah juga lahir dengan tujuan untuk memurnikan tauhid yang dipengaruhi oleh kolonialisme tentang syirik, takhyul, bid'ah dan khurafat dan hidup dalam kemiskinan, kemelaratan dan kebodohan.

Muhammadiyah terus berbenah untuk menjaga eksistensinya dalam memajukan pendidikan di Indoneisa ditandai dengan arah pendidikan ala Muhammadiyah yang konsen menjawab tantangan dan menjemput peluang. Organisasi Muhammadiyah tentang dunia pendidikan sangat memperhatikan kondisi masyarakat yang majemuk dalam pengembangan kurikulum Pendidikan di Indonesia.

\section{Daftar Pustaka}

[1] A. Nata, "Kapita selekta pendidikan Islam: isu-isu kontemporer tentang pendidikan Islam - Abuddin Nata Google Books," Raja Grafindo Persada, 2012. .

[2] D. Supardan, "Menyingkap Perkembangan Pendidkan Sejak Masa Kolonial Hingga Sekarang: Perspektif Pendidikan Kritis," Gener. Kampus, 2008.

[3] A. Rauf, "Peranan Muhammadiyah dalam Pembinaan Generasi Muda Islam di Kabupaten Bima," 2018.

[4] A. Nata, "Peran Pemuda Dalam Sektor Pendidikan," uinjkt.ac.id, 2020. .

[5] I. E. Alamsyah, "Konsistensi Muhammadiyah Mencerdaskan Kehidupan Bangsa," Republika, 2019.

[6] M. Pakkanna, "Jangan Tergesa-gesa Menjadi Orang Muhammadiyah," SUARA MUHAMMADIYAH, 2021.

[7] Sri Sultarini Rahayu \& Riska Angriani BAB, "Peran Organisasi Islam Dalam Pengembangan dan Penerapan Hukum Islam di Indonesia," Ejurnal.Stainparepare.Ac.Id, 2020.

[8] Milya Sari, "Penelitian Kepustakaan (Library Research) dalam Penelitian Pendidikan IPA," Nat. Sci., vol. 6, no. 1, pp. 41-53, 2020.

[9] N. Yusra, "MUHAMMADIYAH: GERAKAN PEMBAHARUAN PENDIDIKAN ISLAM," potensia J. Pendidik. Islam, vol. 4, no. 1, 2018.

[10] N. Al Aydrus, "Peran Muhammadiyah dalam Upaya Pengembangan Pendidikan Islam di Indonesia," IQRA J. Ilmu Kependidikan dan Keislam., vol. 17, no. 1, 2022. 